\title{
Operation Analysis of Coordinated Droop Control for Stand-alone DC Micro-grid
}

\author{
Byung Moon $\mathrm{Han}^{1}$ and Hyun Jun Kim${ }^{2}$ \\ ${ }^{1,2}$ Department of Electrical Engineering \\ Myongji University \\ 38-2 Namdong Cheoingu Yongin Gyeonggi-Do (Korea) \\ Phone/Fax number:+82-31-330-6366, e-mail: erichan@mju.ac.kr ${ }^{1}$, ${\text { inverter1112@ } \text { naver.com }^{2}}^{2}$
}

\begin{abstract}
This paper introduces a coordinated droop control for the stand-alone DC micro-grid., which is composed of photovoltaic generator, wind power generator, engine generator, and battery storage with SOC (state of charge) management system. The operation of stand-alone DC micro-grid with the coordinated droop control was analyzed with computer simulation. Based on simulation results, a hardware simulator was built and tested to analyze the performance of proposed system. The developed simulation model and hardware simulator can be utilized to design the actual stand-alone DC micro-grid and to analyze its performance. The coordinated droop control can improve the reliability and efficiency of the stand-alone DC micro-grid
\end{abstract}

\section{Key words}

stand-alone DC micro-grid, autonomous control, droop control, PV (photo-voltaic) generator, WP (wind power) generator, BES (battery energy storage), SOC (state of charge), MPPT (maximum power point tracking).

\section{Introduction}

Stand-alone micro-grid is a small power grid without any connection with the utility AC grid. It is only composed of renewable power sources, engine generator, BES (battery energy storage), and load. Stand-alone microgrid can be implemented with AC backbone network or DC backbone network.

Stand-alone AC micro-grid has inherent disadvantages related to synchronization, stability, and reactive power. However, stand-alone DC micro-grid does not have these disadvantages. It has relatively lower loss and cost due to the direct connection through one-stage power conversion. Stand-alone DC micro-grid can directly supply power to the digital loads, such as computers, communication devices, and automation devices, which consume DC power internally [1]-[3].

The control method for stand-alone DC micro-grid is divided into two groups. One is a real-time direct control according to the operation mode, in which the generated, stored, and consumed power are measured and transmitted to the main controller through high-speed communication link [4]-[6]. This method can offer highly safe operation for the micro-grid if a fast data transmission between the main controller and the local controllers is possible.

Another is an autonomous control without communication link, in which the converter output voltage is regulated using droop control [7]-[12]. This method improves the performance degradation due to the circulating current among the connected converters. It also brings about frequent transient phenomena and slow dynamic response in regulation process.

This paper introduces a coordinated droop control for stand-alone DC micro-grid. The operation of stand-alone DC micro-grid with coordinated droop control was analyzed using simulation with PSCAD/EMTDC [13]. Based on simulation results, a hardware simulator was built and tested to verify the performance of stand-alone DC micro-grid.

\section{Stand-alone DC Micro-grid}

Fig. 1 shows the configuration of stand-alone DC micro-grid, which is composed of uncontrollable power sources like a WP (wind power) generator and PV (photovoltaic) generator, controllable power source like an engine generator and BES (battery energy storage), and load. It also has a monitoring system through communication link. Each converter has a local controller to manage the operation of each source, BES, and load.

WP generator has a 3-phase AC-DC converter to convert the 3-phase AC power into the DC power. Particularly, the AC-DC converter for WP generator includes a control scheme for MPPT (maximum power point tracking). PV generator has an interleaved boost DC-DC converter to convert the variable DC voltage into the regulated DC voltage.

It also has a control scheme for MPPT. BES has a bidirectional interleaved DC-DC converter to step down the DC grid voltage for charging or step up the battery voltage for discharging. Engine generator and $\mathrm{AC}$ load are connected to the DC grid through the DC-AC converter. And the DC load is connected to the DC grid directly. 


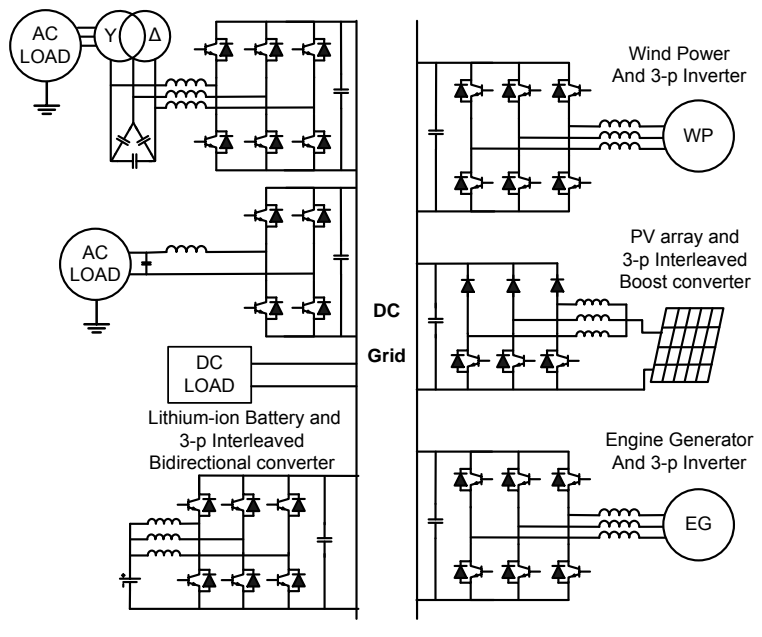

Fig. 1. System structure of stand-alone DC micro-grid

\section{System Operation and Control}

\section{A. Droop Control for BES}

The stand-alone DC micro-grid described in this paper does not use communication link for control purpose, but it uses communication link for monitoring purpose in autonomous control. The BES has a DC voltage control which is shown in Fig. 2.

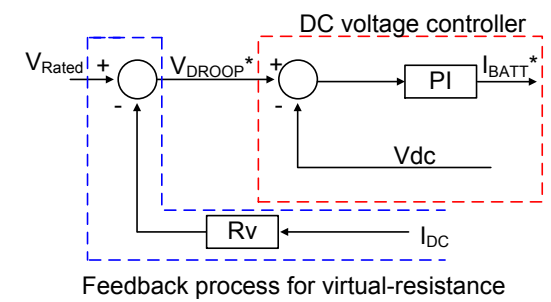

Fig. 2. Droop control for BES

In this paper a feedback loop was added to adjust the droop voltage, in which the DC current $I_{D C}$ is measured and multiplied by the virtual resistance $R_{V}$ to reduce the reference DC droop voltage.

$$
V_{\text {DROOP }}^{*}=V_{\text {Rate }}-R_{V} \times I_{D C}
$$

Therefore, the reference DC voltage can be adjusted by this feedback loop without inserting resistance.

The virtual resistance can be derived considering the tolerable voltage variation as the following equation.

$$
R_{V}=\frac{\Delta V_{d c} \times V_{\min }}{k \times P_{\text {Rate }}}
$$

Where, the $\mathrm{V}_{\min }$ is the minimum DC grid voltage and the $\mathrm{P}_{\text {Rate }}$ is the rated converter capacity.

\section{B. Coordinated Droop Control}

Fig.3 shows an operation scheme for the proposed coordinated droop control method for the controller of BES. The droop curve is divided into three regions according to the DC grid voltage and the battery SOC.

The slope of droop curve in region $\mathrm{A}$ and $\mathrm{B}$ are same and the slope of droop curve in region $\mathrm{C}$ is deferent from that of droop curve in region A and B. So, the virtual resistance is also different, which produces the reference value of droop voltage using equation (1).

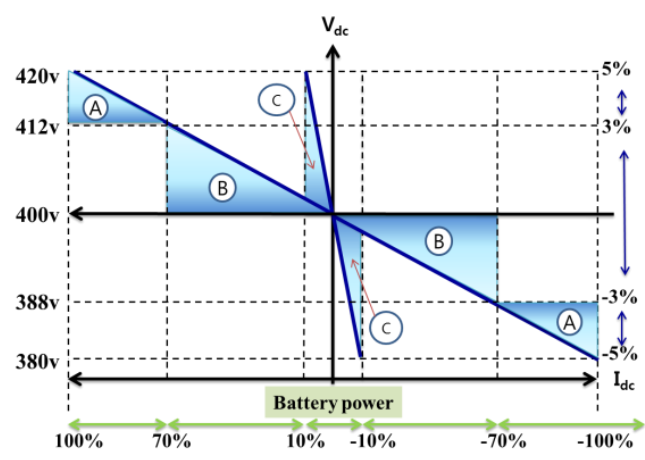

Fig. 3. Coordinated droop control for BES

Region A is located in the DC grid voltage with tolerance of $+3 \sim+5 \%$ or $-3 \% \sim-5 \%$. In this region the battery operates at $70 \% \sim 100 \%$ of rated power. The virtual resistance at this region is obtained from equation (3). At over $+3 \%$ zone the engine generator reduces the output power to handle the surplus power in the DC grid. At under $-3 \%$ zone the engine generator increases the output power to handle the deficient power in the DC grid.

Region B is located in the DC grid voltage with tolerance of $-3 \sim+3 \%$. In this region the battery operates at $0 \% \sim 70 \%$ of rated power. The virtual resistance at this region is obtained from equation (3).

Region $\mathrm{C}$ is defined as a protection zone for over charge and over discharge. In this region, the converter reduces the charging or discharging power immediately to protect the battery. The handling power is about $10 \%$ rated power and the virtual resistance at this region is obtained from equation (4).

$$
\begin{aligned}
& \Delta V_{d c}=20[\mathrm{~V}](5 \%), V_{d c_{-} \min }=380[\mathrm{~V}] \\
& P_{B E S}=5.0[\mathrm{~kW}], R_{B E S}=\frac{\Delta V_{d c} \times V_{d c_{-} \min }}{P_{B E S}}=1.52[\Omega] \\
& \Delta V_{d c}=20[\mathrm{~V}](5 \%), V_{d c_{-} \min }=380[\mathrm{~V}] \\
& P_{B E S}=1.0[\mathrm{~kW}], R_{B E S}=\frac{\Delta V_{d c} \times V_{d c_{-} \min }}{P_{B E S}}=7.6[\Omega]
\end{aligned}
$$




\section{EG Operation Scheme}

The EG operation scheme is described in Fig. 4, in which the EG output power is autonomously controlled according to the voltage variation of DC grid. If the output power of PV and WP is smaller than the power demand in load, the BES discharges power to maintain the power balance in the DC grid.

If the discharged energy increases and the voltage variation decreases down lower than $-3 \%$, the EG output power is repeatedly raised by $\triangle \mathrm{P}$ to maintain the voltage variation at $-3 \%$. When the grid voltage variation is larger than $+3 \%$, the EG output power is repeatedly decreased by $\triangle \mathrm{P}$ to maintain the voltage variation at $+3 \%$. So, the EG output power is autonomously controlled for effective energy management without predicting the load pattern.

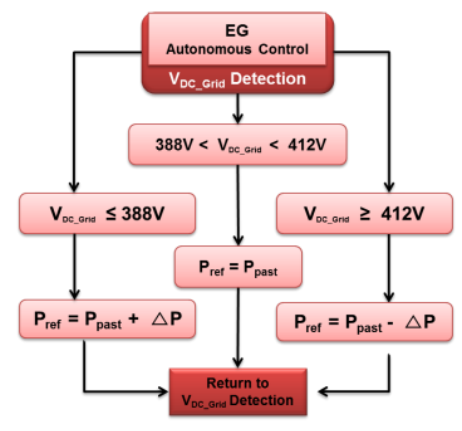

Fig. 4. Operation scheme for EG

\section{PV and WP Operation Scheme}

Since the output power of PV or WP changes continuously according to the weather condition, PV or WP operates in MPPT mode. If the voltage variation of DC grid overreaches at $+5 \%$, it can brings about stability problem in the DC grid. And it overcharges the BES to make shortening the battery life.

Therefore, if the DC grid voltage is higher than $420 \mathrm{~V}$, the PV or WP output power is decreased to reduce the DC grid voltage separately or together. When the DC grid voltage is located under the rated voltage, it means power deficiency in the DC grid. In this case, the output power of PV or WP restart to operates in MPPT mode. So, the output power of PV and WP is autonomously controlled to make the power balance at the DC grid.

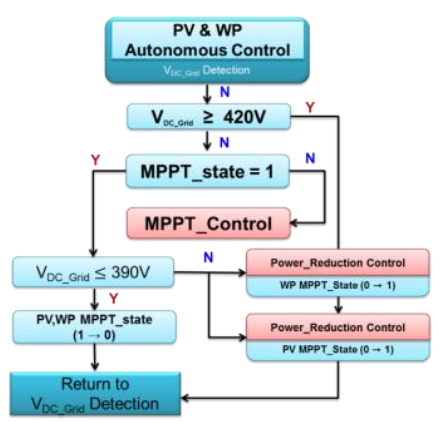

Fig. 5. Operation scheme for PV and WP

\section{E. BES Operation Scheme}

The operation sequence for BES is shown in Fig. 6. When the battery SOC is between $20 \%$ and $80 \%$, powerbalancing control is selected for droop control. Depending on the variation of DC grid voltage, region A, $\mathrm{B}, \mathrm{C}$ are selected.

If the variation of DC grid voltage is less than $-3 \%$ or larger than $+3 \%$, the droop control is carried out in region A. The output power of BES is set at $70 \% \sim 100 \%$ of the rated power. If the variation of DC grid voltage is located between $-3 \%$ and $+3 \%$, the droop control is carried out in region $\mathrm{B}$. The output power of BES is set at $0 \% \sim 70 \%$ of the rated power. The virtual resistance is determined by $1.52 \Omega$.

When the battery SOC is larger than $80 \%$ or less than $20 \%$, the DC grid voltage is checked whether it is higher than $400 \mathrm{~V}$ or not. If higher, the droop control is carried out in region $\mathrm{C}$. The output power of BES is at $10 \%$ of the rated power. If not, the charging mode is changed to the discharging mode or the discharging mode is changed to the charging mode. The virtual resistance is determined by $7.6 \Omega$

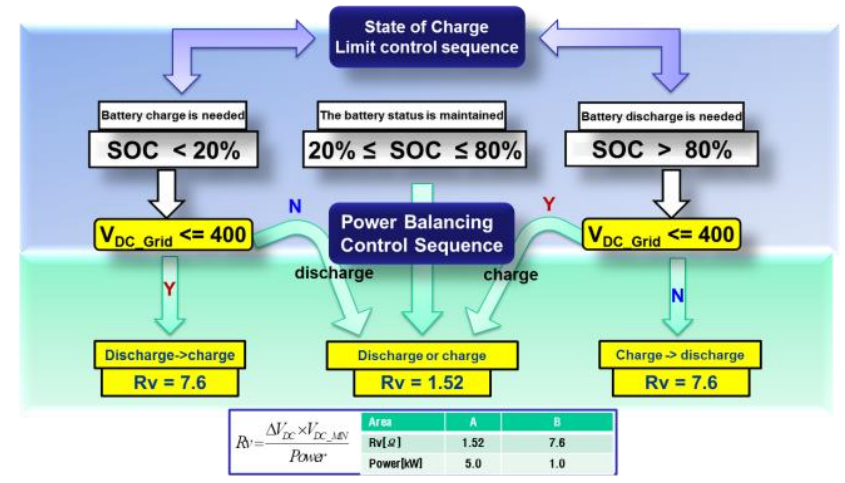

Fig. 6. Operation scheme for BES

\section{Computer simulation}

For the purpose of verifying the coordinated droop control, various simulations were carried out using the PSCAD/EMTDC software. The power circuit and the PWM converter were modeled with the built-in model, where as the PV and WP generators with controllers are implemented with a user-defined model coded in $\mathrm{C}$ language [11].

In order to obtain realistic verification, the simulation models for PV and WP were developed using the built-in model and the user-defined model coded with $C$ language. The voltage and current characteristics of PV were represented using the PV characteristic equation. And the voltage and current characteristics of WP were represented. using wind turbine model and synchronous generator model.

However, As (Ampere-sec) was used in simulation because $\mathrm{Ah}$ is too large to represent the battery capacity in the simulation time of a few ten sec. 
Simulation scenario and checking items were prepared to verify all the operation characteristics of stand-alone DC micro-grid.

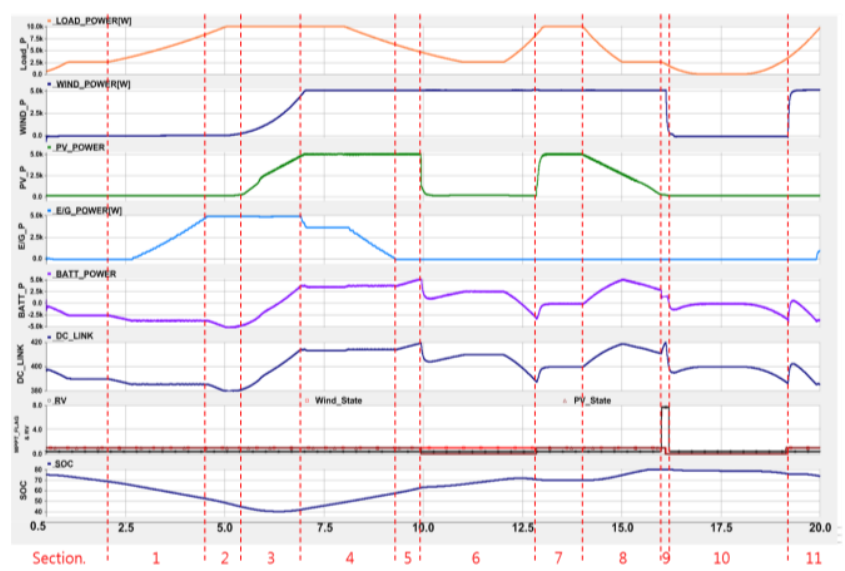

Fig.7. Simulation results for stand-alone DC micro-grid

Table I. Simulation scenario and checking items.

\begin{tabular}{|c|c|c|}
\hline No. & Checking items in Simulation & Region \\
\hline 1 & EG Coordinated Control (Up to+70\% of Rated Battery) & B \\
\hline 2 & $+100 \%$ of Rated Battery Power & A \\
\hline 3 & Distributed Generation Production & B \\
\hline 4 & EG Coordinated Control (Up to -70\% of Rated Battery) & B \\
\hline 5 & $-100 \%$ of Rated Battery Power & A \\
\hline 6 & PV Coordinated Control ( Output Power Reduction) & A \\
\hline 7 & PV Coordinated Control (Maximum Output Power) & A \\
\hline 8 & Battery Charging Mode & B \\
\hline 9 & Droop Curve change (Soc $>80 \%$ \& (Rv : 1.52 $\rightarrow 7.6 \Omega$ ) & C \\
\hline 10 & Wind Coordinated Control (Output Power Reduction) & B \\
\hline 11 & Wind Coordinated Control (Maximum output Power) & B \\
\hline
\end{tabular}

Table I shows all the checking items in each section of simulation time which indicates the operation regions in Fig. 3. Total simulation time is 20 s and 11 time sections are divided to check the operation characteristic.

Fig. 7 shows the simulation results for the coordinated droop control. The 1st, 2nd, 3rd, 4th, 5th graphs show the load power, WP power, PV power, EG power, and BES power respectively. The 6th, 7th, 8th graphs show the DC grid voltage, virtual resistance, and SOC. It is assumed that the load power changes from 0 to $10 \mathrm{~kW}$, and the PV and WP powers change from 0 to $5 \mathrm{~kW}$ so that all the operation regions can be involved.

In section 1, both PV and WP power were set at $0 \mathrm{~kW}$ and the load power slowly increased up to $8.5 \mathrm{~kW}$ in order to make the droop control operates in region $\mathrm{B}$. The BES primarily supplies the load power of $3.5 \mathrm{~kW}$ with $70 \%$ portion and the remaining power from 3.5 to $8.5 \mathrm{~kW}$ is supplied from the EG. Through these graphs the coordinated control of EG can be verified.

In section 2, the load power increased from 8.5 to $10 \mathrm{~kW}$ and the operation region of droop control changed from B to A. Since the EG already supplies $5 \mathrm{~kW}$ power to the load, more required power in load should be supplied from the BES. So, the BES changes the load sharing portion from $70 \%$ to $100 \%$.

In section 3 and 4, both PV and WP power were increased from 0 to $5 \mathrm{~kW}$ and the load power decreased from 10 to $6.5 \mathrm{~kW}$. The operation mode of BES changes from discharging to charging. The output power of EG is reduced from 5 to $0 \mathrm{~kW}$ through coordinated control. The BES is protected from the over-discharge and the operation region changes from $\mathrm{A}$ to $\mathrm{B}$.

In section 5, the PV and WP power is set at the rated power and the load power is reduced. So, even though the EG output power is reduced, the DC grid voltage rises due to the surplus power in the DC grid. Because of the surplus power in the DC grid, the sharing portion of BES is changed from $70 \%$ to $100 \%$.

In section 6 , the load power is decreased down to $2.5 \mathrm{kw}$ and increased up to $8 \mathrm{~kW}$. When the DC grid voltage reaches at $419 \mathrm{~V}$, the $\mathrm{PV}$ power is removed to suppress the rise of DC grid voltage.

In section 7 , the load power is increased from 8 to $10 \mathrm{~kW}$ and the DC grid voltage decreases due to the power deficiency. When the DC grid voltage reaches at $390 \mathrm{~V}$, the PV power is restarted and the operation region changes from A to $\mathrm{B}$.

In section 8 and 9, the PV and WP power is larger than the load power and the BES is slowly charged. When the SOC of battery reaches at the maximum value of $80 \%$, the virtual resistance $\mathrm{Rv}$ is changed from $1.52 \Omega$ to $7.6 \Omega$. The operation region changes from $\mathrm{B}$ to $\mathrm{C}$ and the sharing portion of BES is changed from $70 \%$ to $10 \%$. So, it is verified that the SOC limit is properly managed.

In section 10 and 11 , the power balance can be maintained by reducing the PV, WP, EG powers and managing the SOC limit. AS the load power increases, the WP is restarted when the DC grid voltage reaches at 390V.

Using all the graphs shown in Fig. 7, the checking items described in Table I are verified. It is known that the coordinated droop control described in this paper works properly in three operation regions.

\section{Integration Operation Test}

Based on simulation results, a hardware simulator for stand-alone DC micro-grid was built in the lab. Fig. 8 shows experimental set-up of hardware simulator for integrated operation test. The hardware simulator consists of $5 \mathrm{~kW}$ WP simulator, $5 \mathrm{~kW}$ PV simulator, $5 \mathrm{~kW}$ EG, $5 \mathrm{kWh}$ lithium-polymer battery stack with battery management system, DC micro-grid assembly, PC 
(personal computer) for main controller, and variable AC\&DC load .

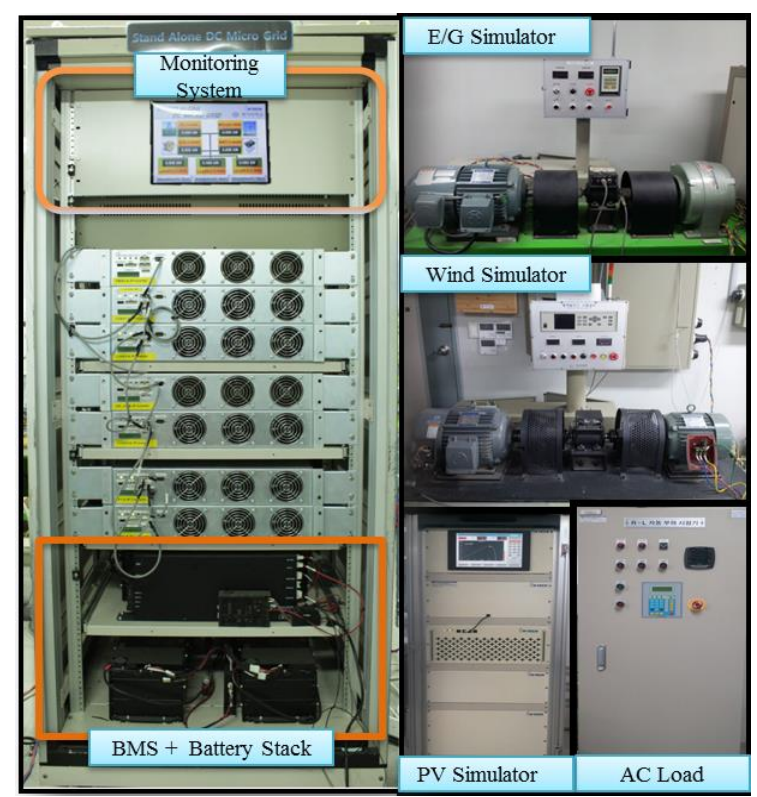

Fig. 8. Experimental set-up

The experimental data of integrated operation test are displayed on the 16-channel oscilloscope. Each converter sub-assembly is mounted on the small iron drawer. DC bus is installed on the back side of DC micro-grid assembly, in which all the output terminal of DGs, BES, and AC\&DC load are connected together.

The wind power simulator and the PV simulator can produce arbitrary output power according to the wind speed and the irradiation. The BES has a BMS (battery management system) which provides SOC data through CAN communication

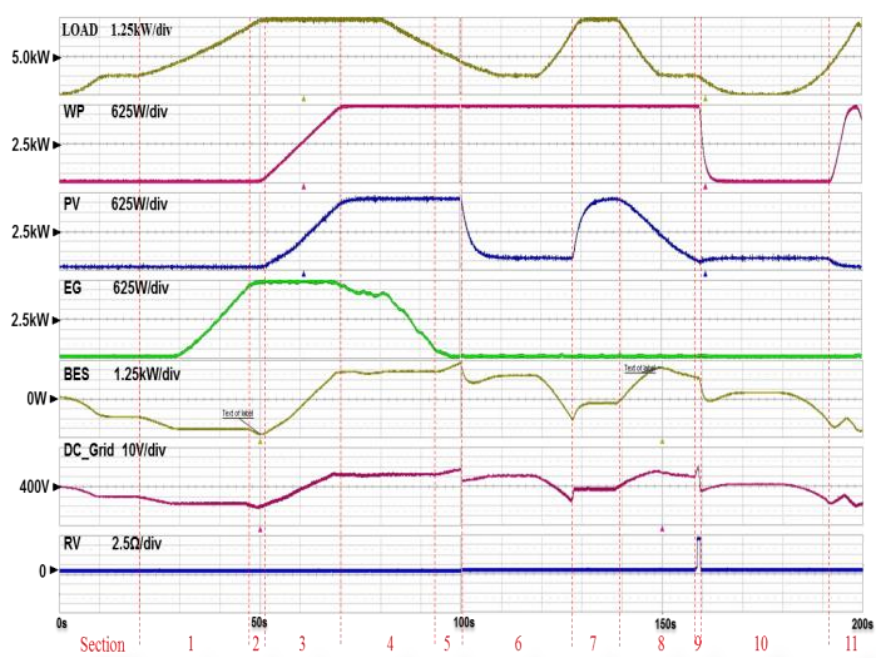

Fig. 9 Experimental set-up for integrated test

Fig. 9 shows the experimental results for the stand-alone DC micro-grid with applying the coordinated droop control. The basic assumptions for the experiment are exactly same as those for simulation. The only difference is the time scale for experiment. The maximum time scale used in the experiment is 200 s, while the maximum time scale used in the simulation is 20 s. All the measured graphs have almost identical shapes to those shown in the simulation. Using all the graphs shown in Fig. 9, the checking items described in Table I are verified experimentally. It is confirmed that the coordinated droop control described in this paper works properly in three operation regions.

Fig. 10 a) shows the measured droop curves for the voltage and current of DC micro-grid, while Fig. $10 \mathrm{~b}$ ) shows the simulated droop curves for the voltage and current of DC micro-grid. Through these two figures it is confirmed that the coordinated droop control for the DC micro-grid operates properly as expected. Therefore, the coordinated droop control can offer very safe operation of DC micro-grid without high transients.

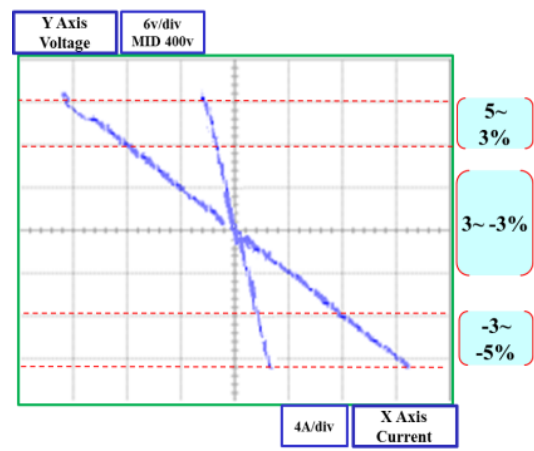

(a)

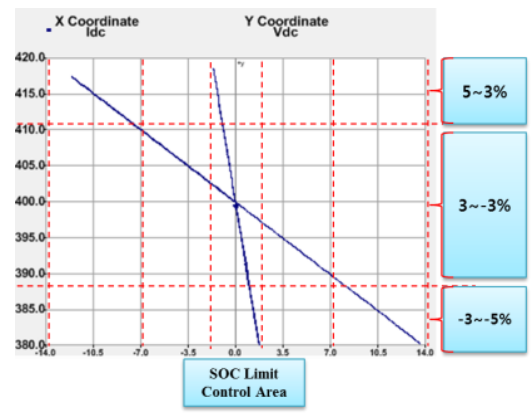

(b)

Fig. 10 Coordinated droop and SOC limit curve

\section{Conclusion}

This paper introduces a new operation method with coordinated droop control for stand-alone DC micro-grid. The proposed coordinated droop control can offer improvement of system reliability and efficiency for the stand-alone DC micro-grid, which is composed of WP, PV, EG and BES with SOC (state of charge) management system. The operation of stand-alone DC micro-grid with proposed control was analyzed using simulation with PSCAD/EMTDC.

Based on simulation results, a hardware simulator was built and tested to analyze the performance of proposed system. The developed simulation model and hardware 
simulator can be utilized to design the actual stand-alone DC micro-grid and to analyze its performance with practical manner.

\section{Acknowledgement}

This work was supported by the Energy Efficiency \& Resources program(No. 20132010101880) of the Korea Institute of Energy Technology Evaluation and Planning(KETEP) grant funded by the Korea government Ministry of Knowledge Economy.

\section{References}

[1] D. Salomonsson, L. Sode, A. Sannino, "An Adaptive Control System for a DC Microgrid for Data Centers", IEEE Transactions on Industry Applications, Vol. 44, No. 6, pp. 1910-1917, Nov, 2008.

[2] H. Kakigano, Y. Miura, T. Ise, "Low-Voltage BipolarType DC Microgrid for Super High Quality

Distribution ", IEEE Transactions on Power Electronics, Vol. 25, No. 12, pp. 3066-3075, Dec , 2010.

[3] P. Biczel, "Power Electronic Converters in DC Microgrid", IEEE CPE'07 (Compatibility in Power Electronics 2007), Gdynia, Poland, May 29-June 01, 2007.

[4] Bi. Rui, Ding. Ming, Xu. Ting Ting, "Design of common communication platform of microgrid", IEEE Power Electronics for Distributed Generation Systems (PEDG), June 16-18, 2010.

[5] A. Ruiz-Alvarez, A. Colet-Subirachs, O. GomisBellmunt, J.M. Fernàndez -Mola, J. López-Mestre, A. Sudria -Andreu, "Design, management and comissioning of a utility connected microgrid based on IEC 61850", Innovative Smart Grid Technologies Conference Europe (ISGT Europe), Oct 11-13, 2010.

[6] Byong-Kwan Yoo, Seung-Ho Yang, Hyo-Sik Yang, Won-Yong Kim, Yu-Seok Jeong, Byung-Moon Han, Kwang-Soo Jang, "Communication Architecture of the IEC 61850-based Micro Grid System", Journal of Power Electronics, vol. 11, no. 3, pp. 350-359, May, 2011.

[7] F. Katiraei, R. Iravani, P. Lehn, "Micro-grid autonomous operation during and subsequent to islanding process", IEEE Trans. on Power Delivery, Vol. 20, No. 1, Jan, 2005.

[8] P. Piagi, R.H. Lasseter, "Autonomous control of microgrids", IEEE PESGM (Power Engineering Society General Meeting), Oct, 2006.

[9] C. Lee, C. Chu, P. Cheng, "A New Droop Control Method for the Autonomous Operation of Distributed Energy Resource Interface Converters", IEEE Transactions on Power Electronics, Vol. pp, No. 99, pp. 1, 2012.

[10] F. Katiraei, R. Iravani, P. Lehn, "Micro-grid autonomous operation during and subsequent to islanding process" IEEE Transaction on Power Delivery, Vol. 20, No. 1, pp. 248-257, Jan, 2005.

[11] B. Meersman, J.D.M. De Kooning, L. Vandevelde, "Analogy Between Conventional Grid Control and Islanded Microgrid Control Based on a Global DCLink Voltage Droop", IEEE Transactions on Power Delivery, Vol. 27, No. 3, pp. 1405-1414, July, 2012.

[12] Il-Yop Chung, Wenxin Liu, David A. Cartes, SooHwan Cho and Hyun-Koo Kang, "Controller Optimization for Bidirectional Power Flow in Medium- Voltage DC Power Systems", JEET, vol. 6, no. 6, pp.750-759, 2011

[13] Ji-Heon Lee, Hyun-Jun Kim, Byung-Moon Han, YuSeok Jeong, Hyo-Sick Yang and Han-Ju Cha, "DC Micro-grid Operational Analysis with a Detailed Simulation Model for Distributed Generations", Journal of Power Electronics, vol. 11, no. 3, pp. 350359, May, 2011.

[14] Jong-Yul Kim, Seul-Ki Kim, June-Ho Park, "Contribution of an Energy Storage System for Stabilizing a Microgrid during Islanded Operation", JEET, vol. 7, no. 6, pp.824-833, 2012

[15] Jong-Yul Kim, Seul-Ki Kim, June-Ho Park, "Coordinated State-of-Charge Control Strategy for Microgrid during Islanded Operation", JEET, vol. 4, no. 2, pp.194-200, 2009 